Index Copernicus Value: 83.27

ISSN (e)-2347-176x ISSN (p) 2455-0450

crossref DOI: _https://dx.doi.org/10.18535/jmscr/v5i8.05

\title{
A Prevalence Study of Intestinal Helminths among Adult Population Attending A Tertiary Care Hospital
}

\author{
Authors \\ Sowmya Nasimuddin $^{1}$, , Jeevan Malaiyan ${ }^{2}$, Akila $\mathbf{K}^{3}$, Mohanakrishnan Kandaswamy ${ }^{4}$ \\ Sumathi Gnanadesikan ${ }^{5}$, Savitha $S^{6}$, Kamalraj $M^{7}$ \\ *Corresponding Author: Sowmya Nasimuddin \\ ${ }^{1,2,3}$ Assistant Professor, ${ }^{4}$ Professor, ${ }^{5}$ Professor \& HOD, ${ }^{6,7}$ Tutor \\ Department of Microbiology \\ 1,2,4,5,6,7 Sri Muthukumaran Medical College Hospital \& Research Institute, Chennai \\ ${ }^{3}$ Meenakshi Medical College Hospital \& Research Institute, Kanchipuram
}

\begin{abstract}
Introduction: Infections caused by intestinal helminths are not so uncommon in endemic regions. Clinical identification of helminthic infections is frequently difficult and laboratory diagnosis with simple tests will help the clinicians in diagnosing and treating the patients. Hence, we did a study to assess the prevalence of intestinal helminths among adult patients attending our tertiary care center.

Materials and Methods: About 1334 freshly collected stool samples from patients attending our hospital (1067 - adult males and 267 - adult females) were included in the study. The stool samples were subjected to macroscopic and microscopic examination with saline and iodine mount. The samples positive for helminths were noted and analyzed.

Results: In our study, out of 1334 samples, 62 (4.6\%) were positive for intestinal helminths, of which 49(79\%) were males and $13(21 \%)$ were females patients. Strongyloides species larvae were found in 28 (45.1\%) samples, Hookworm ova in 23 (37\%), Enterobius vermicularis ova in 6 (9.6\%), Hymenolopsis nana ova in 4 (6.4\%), Trichuris trichiura ova in 3 (4.8\%), and Ascaris unfertilised ovum in 1 sample. We also found the presence of polyparasitism in $5(8 \%)$ samples and all of them were immunocompetant.

Conclusion: The results conclude that intestinal parasites and also polyparasitism are more common in males $(79 \%)$ than females $(21 \%)$ in our area. Strongyloides species forms the major intestinal helminths (45.1\%) followed by hookworms (37\%). Prompt diagnosis, effective treatment, health education, better sanitary measures and evidence-based approaches are required to control intestinal parasitic infections in our country.

Keywords: Intestinal helminths, Strongyloides species, Polyparasitism

Key Messages: Clinical identification of helminthic infections is frequently difficult and laboratory diagnosis with simple tests will help the clinicians in diagnosing and treating the patients. In our study, Strongyloides species forms the major intestinal helminths followed by hookworms. We also noticed the presence of polyparasitism in immunocompetant patients in our study.
\end{abstract}

\section{Introduction}

Infections caused by soil transmitted intestinal developing tropical and subtropical countries. helminths $(\mathrm{STH})$ are widely prevalent in STH infections are one of the most important constituent of NEGLECTED TROPICAL DISEASES (NTD) enlisted by World Health 
Organization (WHO). Even though entirely preventable, they still cause considerable morbidity and mortality ${ }^{1,2}$. According to WHO, the prevalence of STH were more than 2 billions (2014). The factors attributable to the prevalence of these infections are poverty, illiteracy, weather conditions, contaminated water resources and poor sanitation $^{3}$. The epidemiological pattern of these parasites varies with different geographical regions. Diagnoses of such helminthic infections are clinically difficult whereas it can be made easy with simple laboratory tests. In India, the reported prevalence varies from 12.5 to $67 \%{ }^{4}$. Ascaris lumbricoides was the most common intestinal helminthic infection reported in our country. No such studies were available from our area to show the prevalence of intestinal helminthic infections. Hence we did a study to know the prevalence of intestinal helminths among adult patients attending our tertiary care centre.

\section{Subjects and Methods}

Institutional ethical committee approval was obtained prior to the study. A cross sectional study for a period of eight months from December 2015 to July 2016 was conducted in our tertiary care hospital. The study population includes adult male $\&$ female patients attending the hospital during the period of 8 months. A sample size of 1334 samples was included in the study. Out of which 1067 (80\%) were male and 267 (20\%) were female. The stool samples were collected in a wide mouthed container with plastic applicator. The macroscopic examination of the samples was done for color, consistency, presence of mucus, worm segments and $\mathrm{pH}$. The samples were screened in laboratory by routine saline and iodine wet mount and concentration techniques. The samples positive for intestinal helminths were noted and analyzed by frequency and distribution.

\section{Result}

A study to know the prevalence of intestinal helminths among adult population for a period of eight months was conducted in a tertiary care hospital. A total of 1334 samples were collected with $1067(80 \%)$ being male and 267 (20\%) being female. About $62(4.6 \%)$ were positive for intestinal helminths of which $49(79 \%)$ were males and $13(21 \%)$ were females (Figure 1). Strongyloides species (Figure2) were found in 28 $(45 \%)$ of our samples and turned out to be the most common intestinal helminth in our study. Presence of hookworm ova was observed in 23 (37\%) samples, followed by Enterobius vermicularis in $6(9.6 \%)$, Hymenolopsis nana in 4(6.4\%), Trichuris trichura ova in $3(4.8 \%)$ and unfertilised egg of Ascaris in one sample (Figure 3). We also observed the presence of polyparasitism in $5(8 \%)$ of our samples. Patients with polyparasitism were found to be immunocompetant.

Figure 1: Samples included in the study with the rate of positive samples

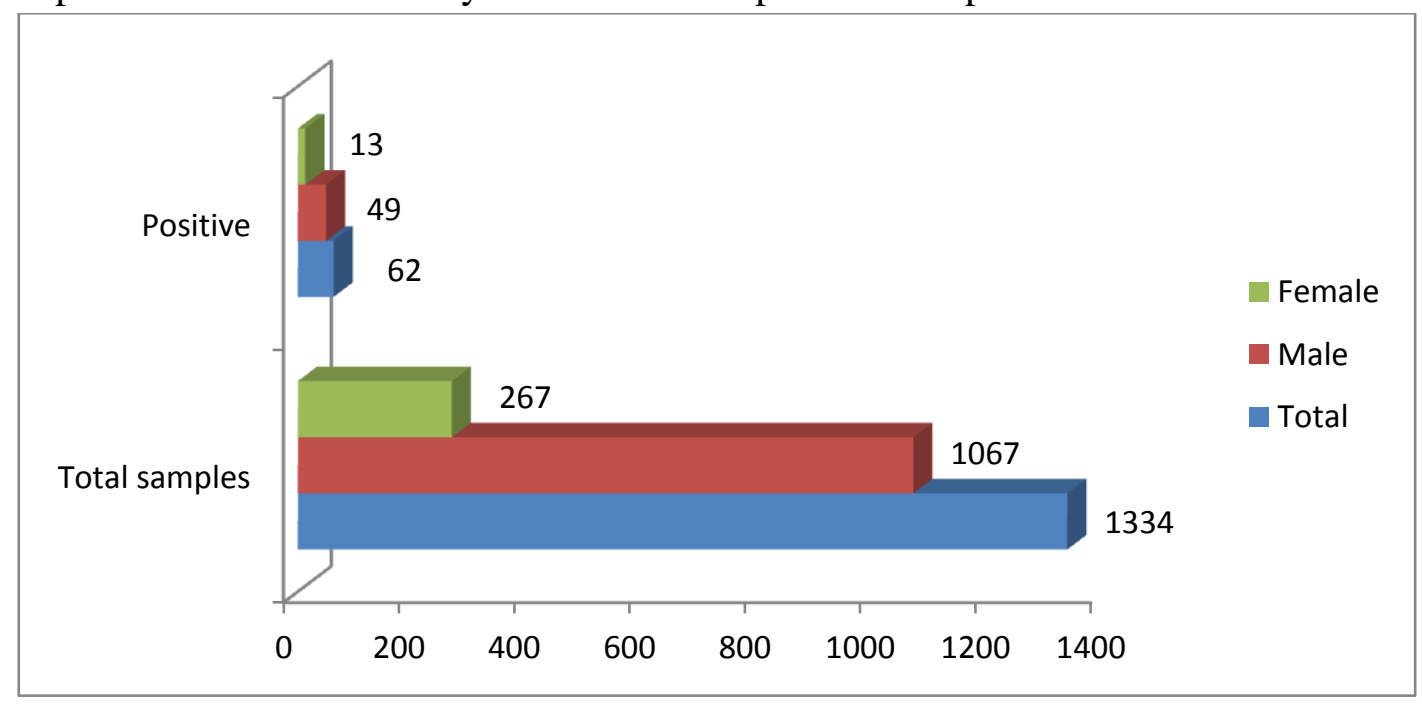


Figure 2. Strongyloides species larvae observed in our study

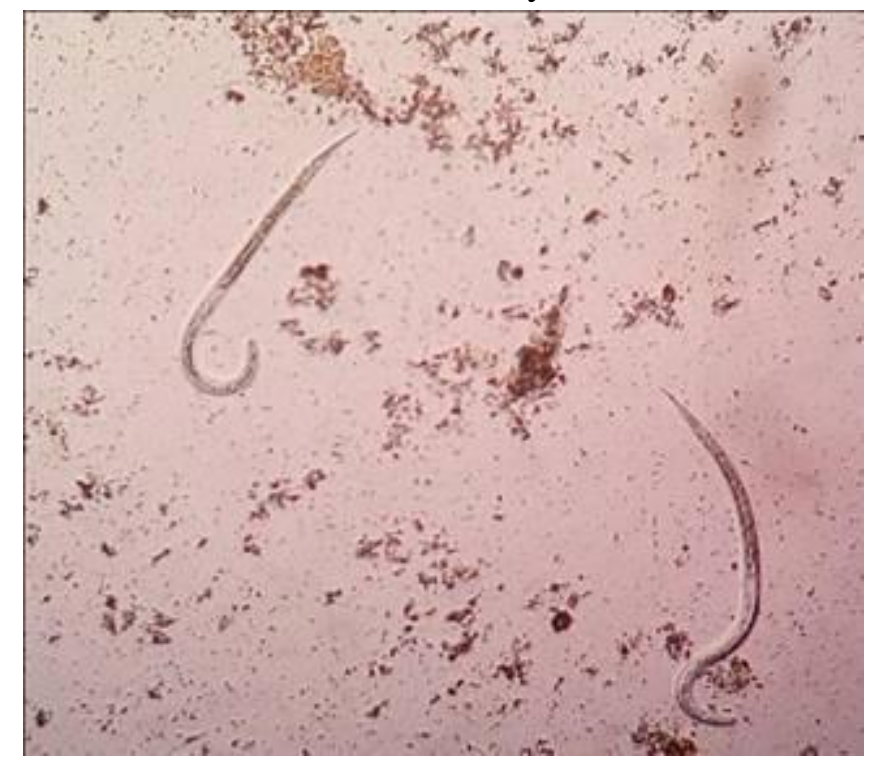

Figure 3: Intestinal helminth isolated in our study

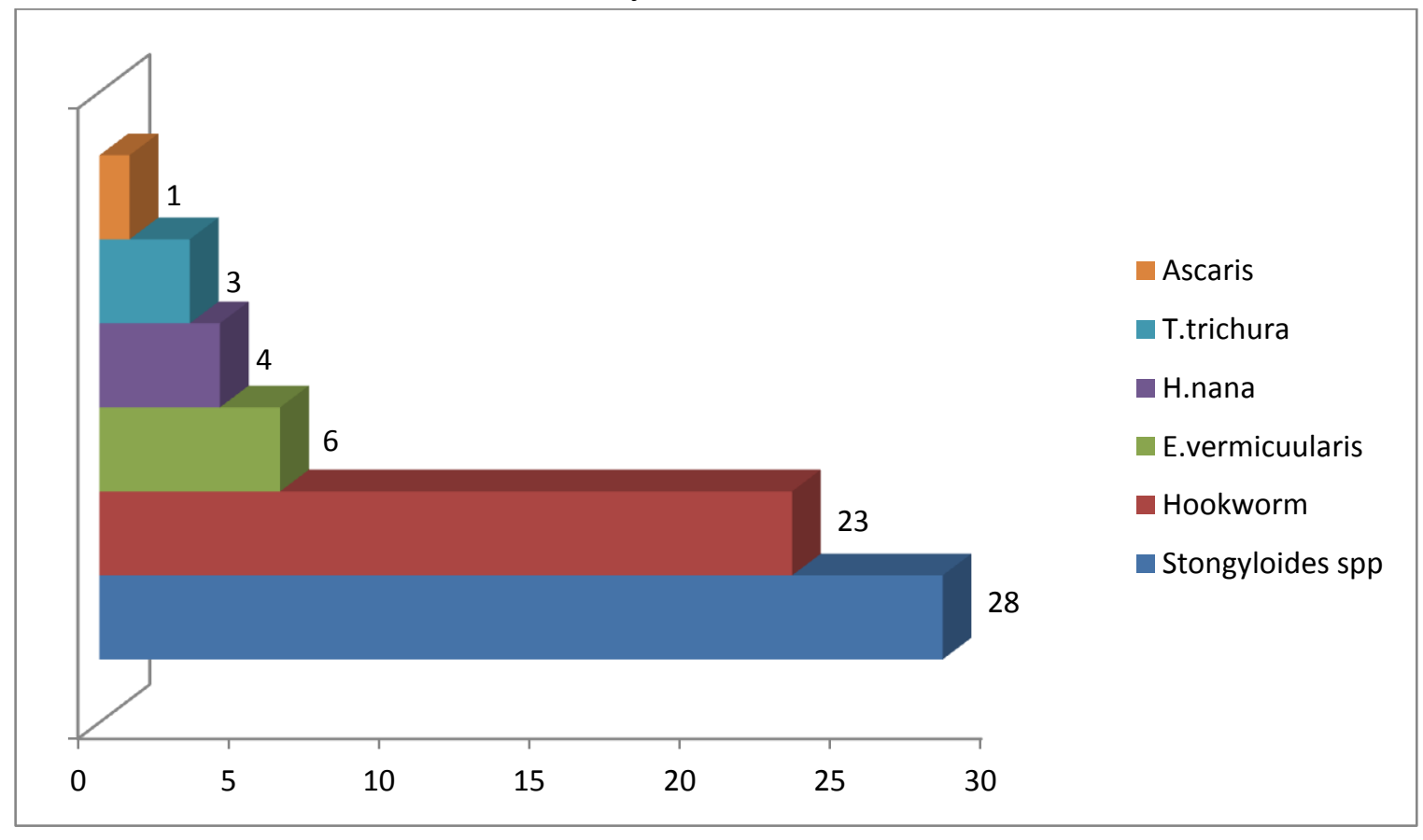

\section{Discussion}

A total of 1334 samples were collected with 1067 (80\%) being male and 267 (20\%) being female to study the prevalence of intestinal helminth. About $62(4.6 \%)$ were positive for intestinal helminths of which $49(79 \%)$ were males and $13(21 \%)$ were females. The prevalence of intestinal helminths in various indian studies ranges from $12.5 \%$ to $67 \%$. The prevalence rate of $7.8 \%$ was observed by Deepthi et al ${ }^{1}$ and $5.97 \%$ by Kumar et al ${ }^{4}$ when compared with our prevalence rate of $4.6 \%$. The prevalence rate among males was found to be more than females in many studies which was similar as observed in our study. Strongyloides species $(45 \%)$ were the most common helminth found in our study followed by Hookworm (37\%). In many studies Ascaris is the most common species followed by hookworm ${ }^{2,5,6}$. The prevalence of Strongyloides species in our area is a notable observation which needs further study regarding sanitation and personal hygiene. We observed that $5 \%$ of our samples were positive for polyparasities. Even though the presence of polyparasitism is more common among 
immunocompromised, there were also few studies to show their presence among immunocompetant as observed in our study ${ }^{7,8}$

The limitations of the study were, we took a single sample from each patient and epidemiological data not included in this study. Future studies can be done with post treatment analysis and with inclusion of epidemiological data. To conclude, this study shows the current pattern of distribution of intestinal helminth parasites in our area. Understanding the burden of these intestinal parasites will help us to improve the public health and sanitation. Effective preventive measures, health education, better sanitary management are the need of the hour along with prompt diagnosis and treatment in developing and under-developed nations.

\section{Acknowledgment}

We herewith acknowledge our institution and all staff members in our department for supporting us in this study.

\section{Conflict of interest: Nil}

\section{References}

1. Deepthi Kattula, Rajiv Sarkar, Sitara Swarna Rao Ajjampur et al. Prevalence \& risk factors for soil transmitted helminth infection among school children in south India. Indian J Med Res 2014; 139 : pp 76-82

2. Brig Hemant Kumar, Capt Kalpana Jain , Maj Rahul Jain. A study of prevalence of intestinal worm infestation and efficacy of anthelminthic drugs. Medical journal armed forces India 2014; 70: 144-48.

3. Sadeghi, H., Borji, H.. A survey of intestinal parasites in a population in Qazvin, north of Iran. Asian Pac. J. Trop. Dis 2015; 5: 231-233.

4. Kumar Manochitra, Shashiraja Padukone, Selvaratthinam, Ajay Philips and Subhash Chandra Parija. 2016. Prevalence of
Intestinal Parasites among Patients attending a Tertiary Care Centre in South India. Int.J.Curr.Microbiol.App.Sci. 5(9): 190-197.

5. Bisht D, Verma AK, Bhardwaj HHD. Intestinal parasitic infestation among children in a semi-urban Indian population. Trop Parasitol. 2011;1(2):104-107.

6. Singh GK, Parajuli KP, Shrestha M, et al. The prevalence of intestinal parasitic infestation in a Tertiary Care Hospital a retrospective study. J Nobel Med Coll. 2013;2:13 - 17.

7. Paul B.Keiser and Thomas B.Nutman. Strongyloides stercoralis in immunocompromised population.Clin Microbiol Rev 2004;17 (1):208 - 17.

8. Rai s, Wadhwa V, Kharbanda P,Uppal B. A case of polyparasitism involving trematode and four different nematodes in a migrant from bihar Indian $\mathbf{J}$ Med Microbiol 2007; 25 (1) : 62-3. 